\title{
Validation of the COTENP Code: A Steady-State Thermal-Hydraulic Analysis Code for Nuclear Reactors with Plate Type Fuel Assemblies
}

\author{
Duvan A. Castellanos-Gonzalez (D), João Manoel Losada Moreira (D), \\ José Rubens Maiorino $\mathbb{D}$, and Pedro Carajilescov \\ Centro de Engenharia, Modelagem e Ciências Sociais Aplicadas, Universidade Federal do ABC, Av. dos Estados 5001, \\ Santo André-SP 09210-508, Brazil
}

Correspondence should be addressed to Duvan A. Castellanos-Gonzalez; duvan.castellanos@ufabc.edu.br

Received 1 September 2018; Accepted 28 October 2018; Published 2 December 2018

Academic Editor: Arkady Serikov

Copyright (C) 2018 Duvan A. Castellanos-Gonzalez et al. This is an open access article distributed under the Creative Commons Attribution License, which permits unrestricted use, distribution, and reproduction in any medium, provided the original work is properly cited.

\begin{abstract}
This article presents the validation of the Code for Thermal-hydraulic Evaluation of Nuclear Reactors with Plate Type Fuels (COTENP), a subchannel code which performs steady-state thermal-hydraulic analysis of nuclear reactors with plate type fuel assemblies operating with the coolant at low pressure levels. The code is suitable for design analysis of research, test, and multipurpose reactors. To solve the conservation equations for mass, momentum, and energy, we adopt the subchannel and control volume methods based on fuel assembly geometric data and thermal-hydraulic conditions. We consider the chain or cascade method in two steps to facilitate the analysis of whole core. In the first step, we divide the core into channels with dimensions equivalent to that of the fuel assembly and identify the assembly with largest enthalpy rise as the hot assembly. In the second step, we divide the hot fuel assembly into subchannels with size equivalent to one actual coolant channel and similarly identify the hot subchannel. The code utilizes the homogenous equilibrium model for two-phase flow treatment and the balanced drop pressure approach for the flow rate determination. The code results include detailed information such as core pressure drop, mass flow rate distribution, coolant, cladding and centerline fuel temperatures, coolant quality, local heat flux, and results regarding onset of nucleate boiling and departure of nucleate boiling. To validate the COTENP code, we considered experimental data from the Brazilian IEA-R1 research reactor and calculated data from the Chinese CARR multipurpose reactor. The mean relative discrepancies for the coolant distribution were below $5 \%$, for the coolant velocity were $1.5 \%$, and for the pressure drop were below $10.7 \%$. The latter discrepancy can be partially justified due to lack of information to adequately model the IEA-R1 experiment and CARR reactor. The results show that the COTENP code is sufficiently accurate to perform steady-state thermal-hydraulic design analyses for reactors with plate type fuel assemblies.
\end{abstract}

\section{Introduction}

Plate type fuel assemblies have been used in research and test due to improved heat transfer surface area. Currently they are considered for small and medium reactors for process heat generation, water desalination applications, and multipurpose reactors [1-4]. Plate type fuels usually consist of a central fuel meat of uranium alloys or uranium composites dispersed in metals and enveloped in a metallic cladding. The fabrication process is usually the picture frame technique with hot rolling in multiple passes and a cold rolling for defining the plate dimensions and surface characteristics.
The fuel assembly consists of a set of such plates regularly spaced to form coolant channels $[5,6]$. These are rectangular and closed in the sides so that no cross flow between neighboring channels can occur. The plate geometry allows a greater ratio of heat transfer area to fuel volume allowing reactor core designs with higher power densities which are beneficial for providing high flux levels for irradiation purposes. The condition of closed coolant channels suggests that simpler physical models to describe the conservation of mass and momentum phenomena may suffice since no mass transfer occurs from one channel to others in its vicinity [7-9]. 
Subchannel thermal-hydraulic codes that handle rectangular channels can be used to verify thermal-hydraulic design limits of plate type fuel reactors. Some of the design parameters include fuel centerline temperatures, flow rate conditions, and local heat transfer conditions based on the estimation of onset of nucleate boiling and departure from nucleate boiling limits [10]. Most subchannel analysis codes were developed for rod type fuels and fewer are dedicated to plate type geometry. Many belong to the COBRA family evolving from the first ones developed in the 1970s [1119]. The COBRA-3C/RERTR code is an example of such developments applied for plate type fuel research and test reactors with low pressure [17]. The literature reports other plate type thermal-hydraulic subchannel codes $[18,19]$ as well as the use of thermal-hydraulic system codes to perform plate type fuel subchannel analysis [20-23]. Most of the subchannel computer codes for plate type reactors reported in the literature are not for general use but dedicated for specific parameter verifications of new research, test, or multipurpose reactors $[17-19,24]$.

In this work we present the validation of the COTENP code (Code for Thermal-hydraulic Evaluation of Nuclear Reactors with Plate Type Fuels) developed for steady-state thermal-hydraulic design evaluation of research and test reactors with plate type fuels and low pressure. The motivation for developing such a computer code was to provide the design team with a tool that allows investigating thermalhydraulic design limits for the reactor named Reator Multipropósito Brasileiro (RMB), a multipurpose reactor with thermal power of $30 \mathrm{MW}$ aimed at producing radioisotopes for medical and industrial applications and material studies with neutrons [25]. The code is based on current literature of subchannel analysis models and its accuracy is validated against experimental and calculated data reported for two reactors with plate type fuels. The first set of data belongs to the Research Reactor Benchmark Database from the International Atomic Energy Agency, more specifically, data from an Instrumented Fuel Assembly (IFA) of the 5 MW IEA$\mathrm{R} 1$ research reactor $[21,22,26]$. The second set of data comes from calculation results for the $50 \mathrm{MW}$ CARR multipurpose reactor [7].

In Section 2 we present the COTENP code methods furnishing details about the conservation equations for mass, momentum, and energy, the flow rate and pressure drop approach, and the numerical approach adopted to solve the equations. In Section 3 we present the data utilized for verifying the accuracy of the COTENP code and the methodology to conduct the validation. In Section 4 we present the comparison results, discussions, and some of the COTENP code capabilities regarding thermal-hydraulic design limits such as the onset of nucleate boiling and departure from nucleate boiling. Finally, in Section 5 we present the concluding remarks.

\section{Methods for the COTENP Code}

In this section work we describe the COTENP code to calculate the thermal-hydraulic parameters of nuclear reactors with plate type fuel elements. To represent the tridimensional behavior of the core we combine the subchannel approach and the cascade method in a two stage scheme as shown in Figure $1[2,5,13,27]$. In the first stage the core is divided into subchannels with size equivalent to a fuel assembly. From the analysis of all core fuel assemblies, the subchannel with the largest enthalpy rise is identified as the hot assembly. In the second stage the hot fuel assembly is divided into subchannels with size equivalent to the actual coolant channel. As in the previous stage, the subchannel with largest enthalpy rise is identified as the hot subchannel. For this subchannel, a detailed thermal-hydraulic analysis is undertaken so that design limits such as maximum temperatures, onset of nucleate boiling, and critical heat flux conditions can be verified.

The conservation equations are solved simultaneously taking into account operational and boundary conditions. The following assumptions were adopted in the code:

(i) Steady-state power and coolant flow

(ii) Uniform inlet and outlet pressure distribution

(iii) Homogeneous equilibrium model for two-phase flow

(iv) One-dimensional heat transfer with uniform transversal heat generation

Each subchannel is divided axially in control volumes. We use mass, momentum, and energy conservation equations for each control volume to obtain along each channel the temperature distribution for the fuel, cladding, and coolant, pressure drop, enthalpy rise, and coolant thermodynamic quality.

Below we describe the conservation equations, the flow rate model, the correlations utilized for determining the onset of nucleate boiling and critical heat flux conditions, and the numerical approach considered in the COTENP code. In Section 3 we present the data and approach considered for verifying the accuracy of the COTENP code.

2.1. Conservation Equations for Mass, Momentum, and Energy. Figure 2 shows schematically the subchannel approach used to represent the coolant behavior and the variables pertaining to the three conservation equations. The $\mathrm{k}_{\mathrm{th}}$ subchannel is divided into axial control volumes allowing the simultaneous solution of the conservation equations for mass, energy, and momentum.

The steady-state conservation equations for the $\mathrm{k}_{\mathrm{th}}$ subchannel and $i_{\text {th }}$ control volume are described below. The mass conservation sketched in Figure 2a is

$$
\begin{aligned}
\dot{m}_{k, i}-\dot{m}_{k, i+1} & =0 \\
\dot{m}_{k, i} & =\rho_{k, i} \bar{u}_{k, i} A_{k}
\end{aligned}
$$

where $\dot{m}_{k, i}$ is the coolant mass flow rate $(\mathrm{kg} / \mathrm{s}), \rho$ is the coolant specific mass $\left(\mathrm{kg} / \mathrm{m}^{3}\right), \bar{u}_{k, i}$ is the coolant speed $(\mathrm{m} / \mathrm{s})$, and $A_{k}$ is the cross section area of the subchannel $\left(\mathrm{m}^{2}\right)$. 


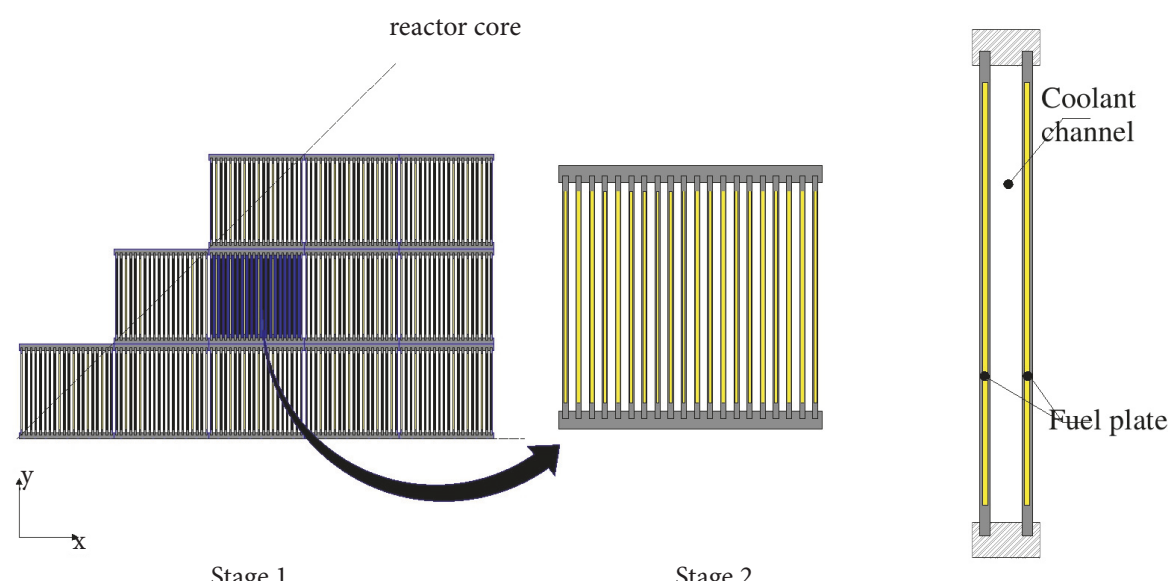

Stage 1

Stage 2

Size subchannel equivalent to the fuel assembly
Size subchannel equivalent to the one channel
Critical channel

FIGURE 1: The chain method for the two stage approach of the COTENP code.

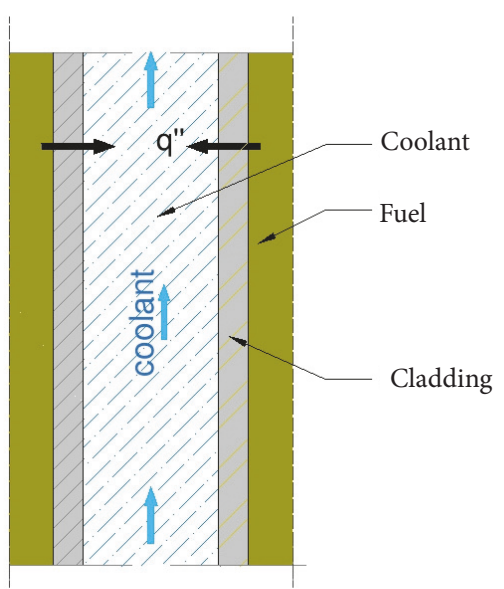

Scheme to a single channel

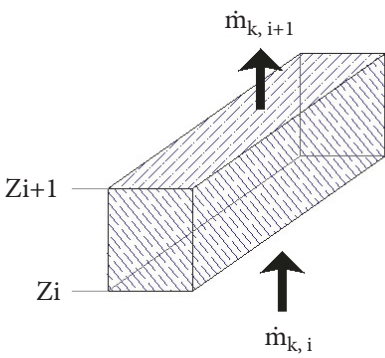

a. Mass Equation

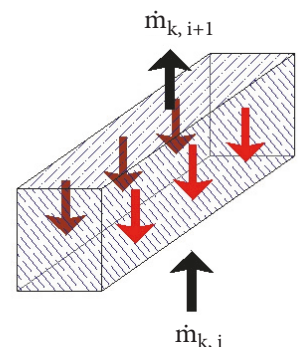

b. Momentum Equation

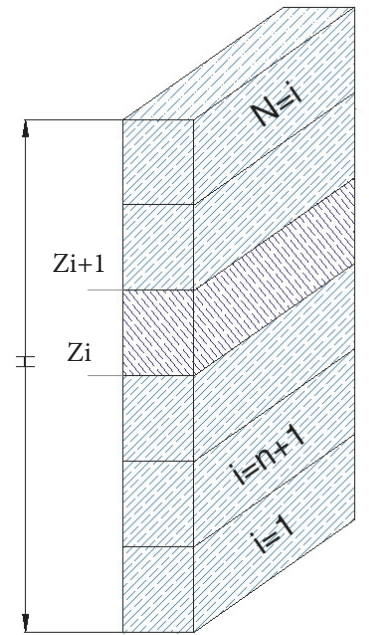

Sub-channel approach

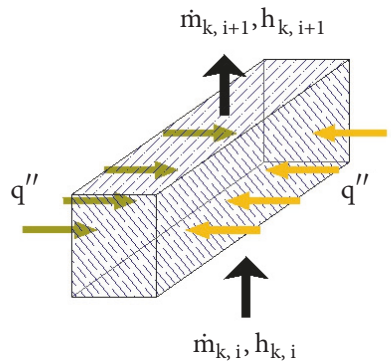

c. Energy Equation

Figure 2: Representation of the conservation equations in the $\mathrm{i}_{\mathrm{th}}$ control volume of the $\mathrm{k}_{\mathrm{th}}$ subchannel. $\mathrm{H}$ is the subchannel length, $\mathrm{L}$ is the plate side length, and $\mathrm{d}$ is the distance between plates or coolant channel width. 
The momentum conservation equation sketched in Figure $2 b$ is

$$
\begin{aligned}
\Delta P_{k, i}= & f_{k, i} \frac{\left(Z_{k, i+1}-Z_{k, i}\right) \rho_{k, i} \bar{u}_{k, i}^{2}}{2 D_{h}}+k_{k, i} \frac{\rho_{k, i} \bar{u}_{k, i}^{2}}{2 D_{h}} \\
& +\rho_{k, i} g\left(z_{k, i+1}-z_{k, i}\right)+\frac{\dot{m}_{k}}{2 \rho_{k, i}}\left(\frac{1}{A_{i+1}^{2}}-\frac{1}{A_{i}^{2}}\right)
\end{aligned}
$$

where $\Delta P_{k, i}$ is the total pressure drop in the $(\mathrm{k}, \mathrm{i})_{\text {th }}$ control volume, $f_{k, i}$ is the friction coefficient, $\mathrm{z}_{\mathrm{k}, \mathrm{i}}$ is the control volume elevation in the subchannel, $D_{h}$ is the hydraulic diameter of the subchannel, and $k_{k, i}$ is the localized form loss coefficient. In the RHS of (3) the first term accounts for friction losses, the second term accounts for form losses, the third term accounts for elevation losses, and the fourth term accounts for acceleration losses. The friction coefficient is given by the Hangen-Poiseulle correlation for laminar flows and by the Blasius correlation for turbulent flows [30].

We can define a hydraulic resistance $R_{k, i}$ grouping the first two terms in the RHS of (3)

$$
R_{k, i}=f_{k, i} \frac{\left(Z_{k, i+1}-Z_{k, i}\right) \rho_{k, i}}{2 D_{h}}+k_{k, i} \frac{\rho_{k, i}}{2 D_{h}}
$$

and rewrite it as

$$
\begin{aligned}
\Delta P_{k, i}= & R_{k, i} \bar{u}_{k, i}^{2}+\rho_{k, i} g\left(z_{k, i+1}-z_{k, i}\right) \\
& +\frac{\dot{m}_{k}}{2 \rho_{k, i}}\left(\frac{1}{A_{i+1}^{2}}-\frac{1}{A_{i}^{2}}\right) .
\end{aligned}
$$

The energy conservation equation sketched in Figure $2 \mathrm{c}$ is

$$
\dot{m}_{k}\left(\bar{h}_{k, i+1}-\bar{h}_{k, i}\right)=q_{x k, i}^{\prime \prime} P_{a} \Delta z
$$

where $\bar{h}_{k, i}$ is the coolant enthalpy (J/kg), $q_{x k, i}^{\prime \prime}$ is the heat flux across the surface area of the fuel plate $\left(\mathrm{W} / \mathrm{m}^{2}\right)$, and $P_{a}$ is the heated perimeter of the subchannel $(\mathrm{m})$. The heat flux is given by

$$
q_{k, i}^{\prime \prime}=q_{\max }^{\prime \prime} F_{k, i}^{N}
$$

where $F_{k, i}^{N}$ is the power density distribution factor in the $\mathrm{k}_{\mathrm{th}}$ subchannel and $i_{\text {th }}$ control volume which accounts for the fission heat generation in the core. The $F_{k, i}^{N}$ can be calculated as the product of axial and fuel assembly (radial) peak factors $\left(F_{k, i}^{N}=F_{k, i}^{A} F_{k, i}^{R}\right)[9,29,31]$.

The temperature profile across the fuel plate is determined assuming perfect contact between the fuel meat and the cladding. Thus the heat transfer process considered inside the plate is conduction whereas the one between the cladding and the coolant is convection. The resulting temperature equations for the coolant, cladding, and fuel centerline are presented elsewhere [31].

2.2. Homogeneous Equilibrium Model for Two-Phase Flow. The COTENP code model assumes the homogeneous equilibrium model for the two-phase flow phenomena in the reactor core. This model assumes a homogenous flow in which there is no relative velocity between vapor and liquid phases in thermodynamic equilibrium [32]. The possible occurrence of two-phase flow is determined relating the flow enthalpy with the saturation enthalpies of vapor and liquid at local pressure and temperature conditions determined by the code. The thermodynamic quality evaluation along the subchannel is given by

$$
x_{k, i}=\frac{\bar{h}_{\mathrm{k}, \mathrm{i}}-\bar{h}_{l}}{\bar{h}_{\mathrm{v}}-\bar{h}_{l}}
$$

where $\bar{h}_{k, i}, \bar{h}_{l}$ and $\bar{h}_{v}$, are the control volume enthalpy and the corresponding liquid and vapor saturations enthalpies with respect to the control volume pressure and temperature.

For thermodynamic quality values below zero it is considered a monophasic liquid flow while for values greater than zero it is considered two-phase flow condition. At this point, the coolant behavior is represented by a fictitious flow, which obeys the conservation equation presented above and requires the coolant properties to be given by average twophase flow parameters. The coolant specific mass $\left(\rho_{\mathrm{k}, \mathrm{i}}\right)$ and coolant velocity $\left(u_{k, i}\right)$ are then given by

$$
\begin{aligned}
\frac{1}{\bar{\rho}_{k, i}} & =\frac{x_{k, i}}{\left(\bar{\rho}_{k, i}\right)_{v}}+\frac{1-x_{k, i}}{\left(\bar{\rho}_{k, i}\right)_{l}} \\
\text { and } \bar{u}_{k, i} & =\frac{\bar{u}_{k, i} \bar{\rho}_{k, i} A_{k, i}}{\bar{\rho}_{k, i} A_{k, i}} .
\end{aligned}
$$

2.3. Flow Rate Model Based on Balance of Pressure Drop. The flow rate in each subchannel is obtained by imposing the same pressure drop for all subchannels from the inlet to the outlet. This procedure is normally utilized to determine cross flow between neighboring coolant channels in rod bundles $[14,16]$. In this work we apply it to determine the channel flow rate of closed channels in plate type fuels. This is done in an iterative process in which the coolant velocity is adjusted until all subchannels present the same pressure drop within a convergence criterion. Figure 3 shows the scheme in which the velocity initial uniform produces a variable pressure drop. In the iterative process the coolant velocity is varied to equate the pressure drop of all different subchannels. The procedure is stopped when a convergence criterion is reached.

To show how the subchannel flow rate is determined consider that the initial (first iteration) total mass flow rate for the reactor core is given by

$$
\dot{m}_{T O T}=A_{T} \sum_{k=1}^{K} \rho_{k} \alpha_{k} \bar{u}_{k, 0}
$$

where $\dot{m}_{T O T}$ is the core mass flow $(\mathrm{kg} / \mathrm{s}), A_{T}$ is the total flow cross section area of the core, $\rho_{k}$ is the coolant density $\left(\mathrm{kg} / \mathrm{m}^{3}\right), \bar{u}_{k, 0}$ is the first iterate average velocity of the coolant $(\mathrm{m} / \mathrm{s}), \alpha_{k}=A_{k} / A_{T}$, and $A_{k}$ is the cross section area of the subchannel; the subscript $k$ refers to the subchannel number within the set of the $\mathrm{K}$ subchannels in the given stage. 

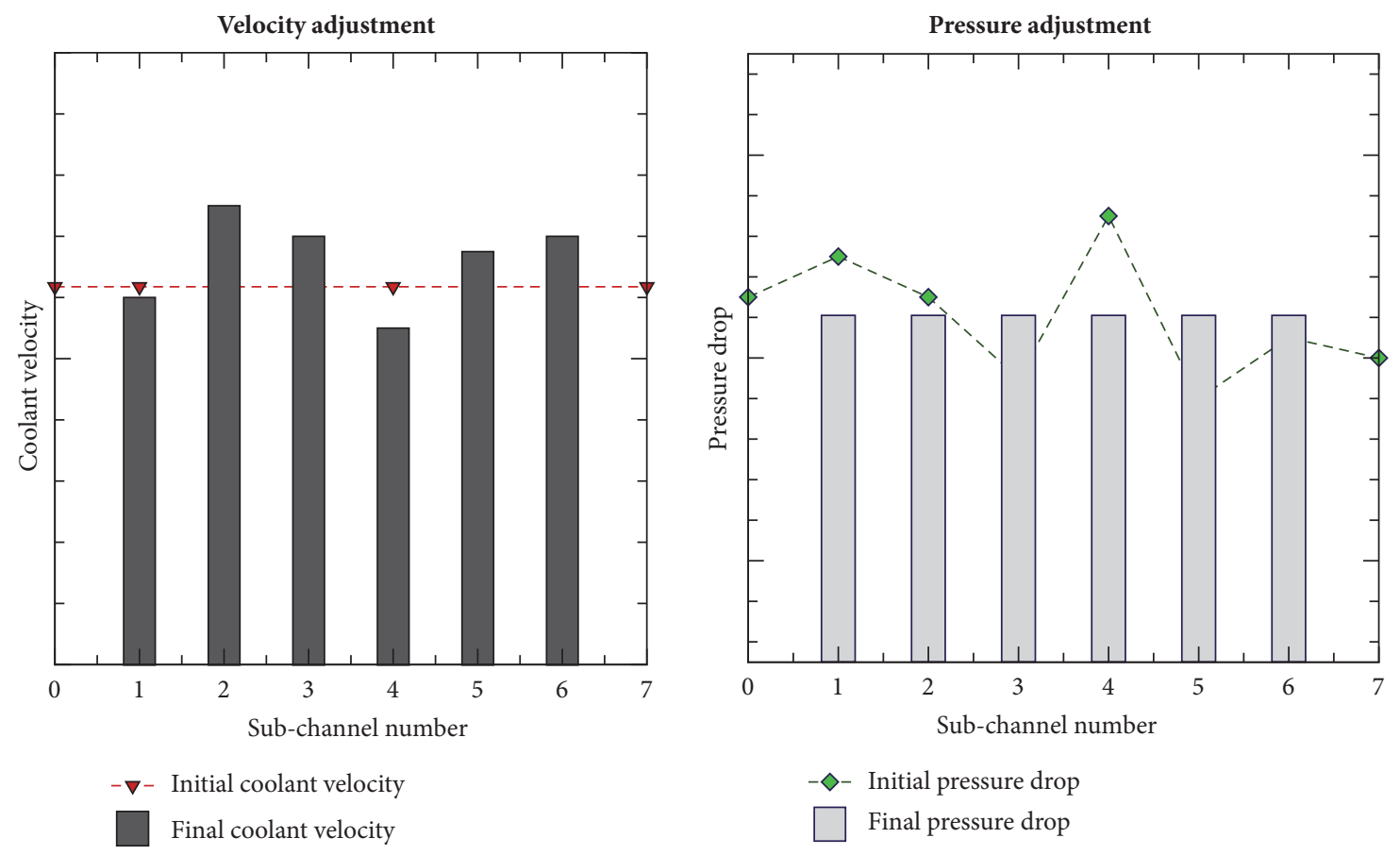

FIgURE 3: Model of mass flow rate distribution used in COTENP code.

In the iterative process the coolant velocity is changed from one step to the next to find the velocity distribution that adjusts the pressure drop of all subchannels, i.e.,

$$
\bar{u}_{k}=\bar{u}_{k, 0}+\Delta \bar{u}_{k}
$$

where $\Delta \bar{u}_{k}$ is the velocity change. Equation (11) then turns to

$$
\dot{m}_{\text {TOT }}=A_{T}\left(\sum_{k=1}^{K} \rho_{k} \alpha_{k} \bar{u}_{k, 0}+\sum_{k=1}^{K} \rho_{k} \alpha_{k} \Delta \bar{u}_{k}\right) .
$$

Since the first term equals $\dot{m}_{T O T}$, the second term of (13) must be zero, i.e.,

$$
\sum_{k=1}^{N} \rho_{k} \alpha_{k} \Delta \bar{u}_{k}=0
$$

The pressure drop for the $(\mathrm{k}, \mathrm{i})_{\text {th }}$ control volume is calculated using (5) of momentum conservation neglecting the less influential terms and keeping the friction and form losses as follows:

$$
\Delta P_{k, i}=R_{k, i} \bar{u}_{k, i}^{2}
$$

The pressure drop across the subchannel is given by

$$
\Delta P_{k}=\sum_{i=1}^{N} \Delta P_{k, i}=R_{k} \bar{u}_{k}^{2} .
$$

Substituting (12) in (16) and neglecting the second order term in $\Delta \bar{u}_{k}$ we obtain

$$
\Delta P_{k}=\Delta P_{k, 0}+2\left(\frac{\Delta P_{k, 0}}{\bar{u}_{k, 0}}\right) \Delta \bar{u}_{k}
$$

From the condition of balanced pressure drop for all subchannels, i.e., $\Delta p_{k}=\Delta p_{j}$, we obtain the coolant velocities that meet these requirements. This is a under determined problem for the case of two subchannels or over determined for 3 or more subchannels. Therefore $\Delta \bar{u}_{k}$ is obtained iteratively as presented in Section 2.5.

\subsection{Onset of Nuclear Boiling and Departure from Nuclear Boil-} ing Correlations. The heat transfer design limits are related to inadequate heat transfer to the coolant in core regions with high peak power densities. The limiting conditions depend on peak power density in the fuel meat and local coolant conditions such as pressure, quality, and temperature and are related to the nucleate boiling heat transfer condition. The parameters used to verify design limits are the onset of nucleate boiling $(\mathrm{ONB})$ and departure from nucleate boiling (DNB) $[2,9,10]$.

To predict the ONB the code furnishes three different correlations: Bergles and Rohsenow (1964), Jens and Lottes (1951), and one developed for narrow rectangular channels proposed by Al-Yahia and Jo (2017) [10].

The departure from nucleate boiling ratio is defined as

$$
D N B R=\frac{q_{D N B}^{\prime \prime}}{q_{\text {Local }}^{\prime \prime}}
$$

where $q_{D N B}^{\prime \prime}$ is the critical heat flux furnished by the EPRI correlation [2] and $q_{\text {Local }}^{\prime \prime}$ is the local heat flux calculated by the COTENP code.

2.5. Numerical Solution Approach. The main program controls 5 modules: (I) input parameters; (II) geometrical 


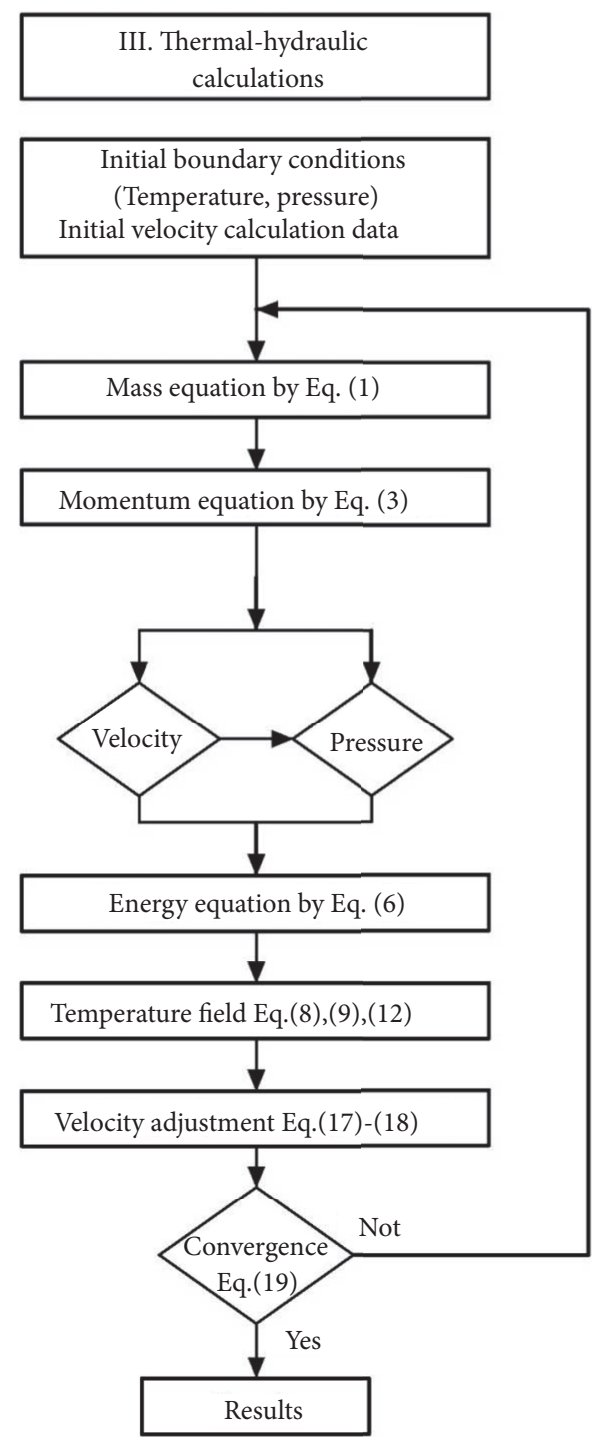

FIGURE 4: Calculation procedure for stages 1 and 2 in Module (III).

parameter calculations; (III) thermal-hydraulic calculations (coolant velocity estimation, conservation equations, and temperature distribution estimation); (IV) estimation of critical heat flux and onset of nucleate boiling conditions; and (V) output results. The code was developed using FORTRAN language.

Figure 4 shows the flow chart of the thermal-hydraulic calculation scheme, module (III). The code conducts the first and second stage calculations according to the size of the subchannels under study. Before starting the second stage, the code estimates the intra-assembly radial power factor for each subchannel through values of average power factors from neighboring assemblies using the Thomas algorithm [33].

The scheme for determining the flow rate through pressure drop balance requires varying the coolant velocity to equate all subchannels pressure drops. We start considering (17) and equating the $\Delta \mathrm{P}$ for subchannels $\mathrm{k}+1$ and $\mathrm{k}$, i.e.,

$$
\Delta P_{k+1}=\Delta P_{k} .
$$

From (19) we obtain the initial coolant velocity for subchannel $\mathrm{k}+1$

$$
\begin{aligned}
\Delta \bar{u}_{k+1,0}= & \frac{\bar{u}_{k+1,0}}{2}\left(\frac{\Delta P_{k, 0}}{\Delta P_{k+1,0}}-1\right) \\
& +\left(\frac{\Delta P_{k, 0}}{\Delta P_{k+1,0}}\right)\left(\frac{\bar{u}_{k+1,0}}{\bar{u}_{k, 0}}\right) \Delta \bar{u}_{k} .
\end{aligned}
$$

Then, to make sure that the total flow rate does not change we adjust the coolant velocity in each channel to obey (14), i.e.,

$$
\Delta \bar{u}_{k}=-\frac{1}{\rho_{k} \alpha_{k}} \sum_{\substack{j=1 \\ j \neq k}}^{N} \rho_{j} \alpha_{j} \Delta \bar{u}_{j, 0} .
$$

where $\Delta \bar{u}_{j}^{0}$ is given by (20). The process to calculate the redistribution of the coolant velocity is iterative using Equations (19) through (21) until the convergence criterion $\epsilon$ is reached. 


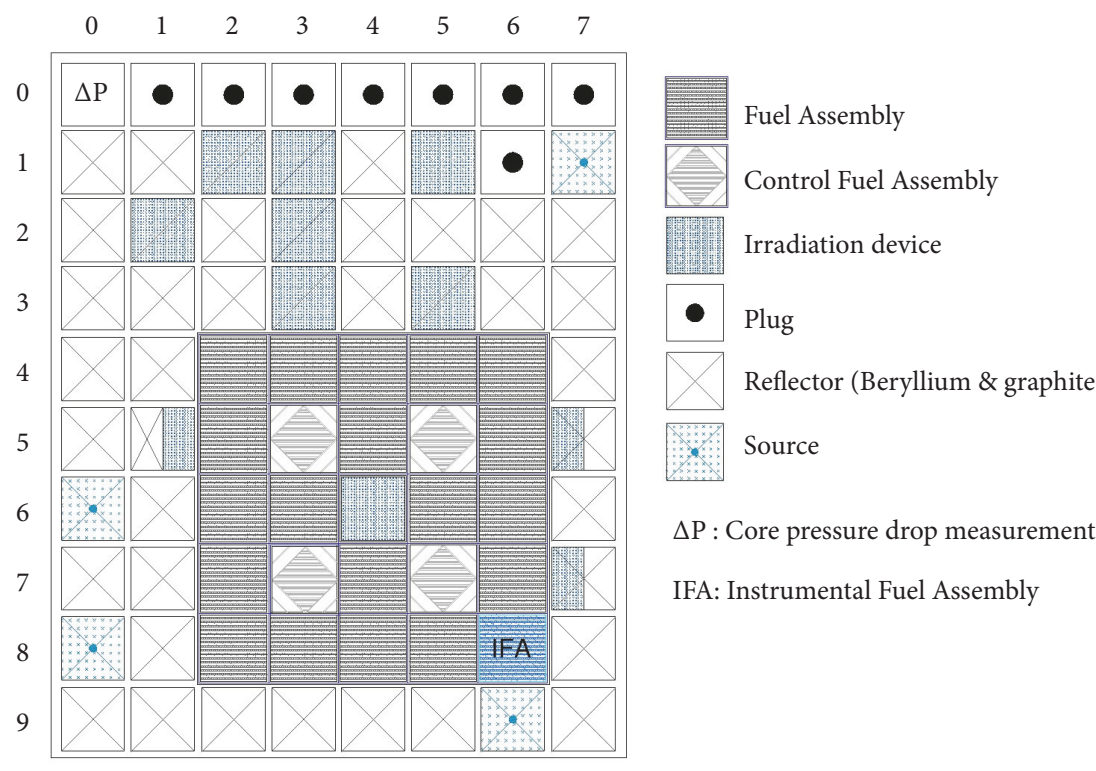

Figure 5: Top view of configuration 243 of the IEA-R1 nuclear core. Adapted from [26].

\section{Validation Approach and Data}

The validation of the COTENP code is conducted using experimental data from the IEA-R1 research reactor and calculated results reported for CARR multipurpose reactor. The thermal-hydraulic variables of subchannel analyses of plate type fuel reactors found in the literature are coolant, cladding, and fuel axial temperature distributions, fuel assembly flow rate distribution, pressure drops across the reactor core, mean coolant velocity in subchannels, and departure from nucleate boiling results. Below we describe the IEA-R1 research reactor and the CARR multipurpose reactor and their reported subchannel analysis data $[7,22,26,28,34]$ and the approach taken in this work to carry out the COTENP code validation.

3.1. The IEA-R1 Research Reactor. The validation of the COTENP code is based on the experimental data presented in the Benchmark Database of the International Atomic Energy Agency from the IEA-R1 research reactor [26]. The IEA-R1 is an open pool type research reactor with $5 \mathrm{MW}$ maximum thermal power using low enrichment MTR $\mathrm{U}_{3} \mathrm{Si}_{2}$ $\mathrm{Al}$ and $\mathrm{U}_{3} \mathrm{O}_{8}-\mathrm{Al}$ dispersed fuel assemblies. The reactor heat removal occurs through a downward coolant flow. The core comprises 20 regular fuel assemblies each one with 18 fuel plates assembled in two lateral support plates conforming 17 closed flow channels heated on two sides, and 4 control fuel assemblies. The irradiation positions are located in the center of the core and in the reflector region. Figure 6 shows the top view of configuration 247 and more information about the IEA-R1 reactor can be found in Appendix A.
The reactor is equipped with an Instrumented Fuel Assembly (IFA) allowing measurements of coolant and cladding temperatures, flow rate and fuel assembly power, and with a dummy fuel assembly $(\Delta \mathrm{P})$ without fuel utilized for measuring flow rate, pressure drop and other variables. Figure 5 shows the top of view of configuration 243, the IFA positioned in location $(6,8)$, and the dummy assembly positioned in location $(0,0)$ [26].

The IFA temperature experimental data comprise 14 measurement locations of coolant and cladding temperatures distributed as shown in Figure 7. There are two thermocouples to measure coolant inlet and outlet temperatures and 12 thermocouples distributed in three channels. The coolant flow rate and pressure drop experimental data were measured using the dummy fuel assembly. The coolant velocity was obtained from the coolant flow rate measurements. Figure 6 shows thermocouples positions in the IFA and Table 1 shows the measured variables and their respective locations.

Reference [26] does not present the experimental error for the temperature data but furnishes data plots from which they extracted their average values. Observing maximum variations in the data plot intervals we can infer that they are below $0.25^{\circ} \mathrm{C}$ or about $0.5 \%$ of the mean temperatures reported [26]. We take this variation as the experimental error for all temperature data.

Reference [22] reports total core pressure drop measured with the dummy but does not present details such as exact location of the measurements and their experimental error.

3.2. The CARR Multipurpose Reactor. The second set of data used to verify the COTENP code came from the CARR 


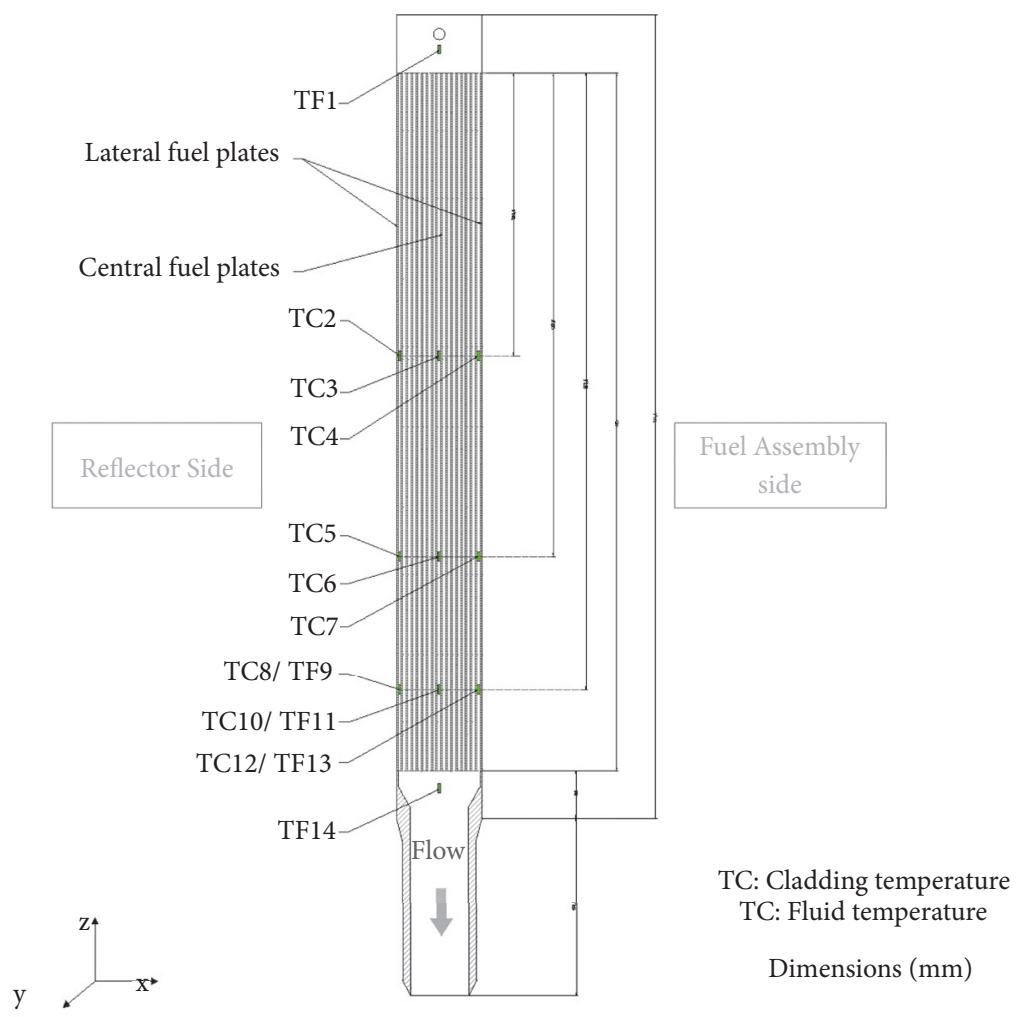

FIgURE 6: Thermocouples positions in the Instrumental Fuel Assembly (side view). Adapted from [26].

TABLE 1: Measurement variables from the IEA-R1 reactor utilized in the COTENP code validation. Temperature variables are measured in the IFA and flow rate and pressure drop are measured in the dummy fuel assembly $(\Delta \mathrm{P})[22]$.

\begin{tabular}{lcc}
\hline Label & Location & Measurement variable \\
\hline TC2 & cladding lateral plate (side reflector) & Temperature (IFA) \\
TC3 & cladding central plate & Temperature (IFA) \\
TC4 & cladding lateral plate (side fuel assembly) & Temperature (IFA) \\
TC5 & cladding lateral plate (side reflector) & Temperature (IFA) \\
TC6 & cladding central plate & Temperature (IFA) \\
TC7 & cladding lateral plate (side fuel) assembly & Temperature (IFA) \\
TC8 & cladding lateral plate (side reflector) \\
TC10 & cladding central plate & Temperature (IFA) \\
TC12 & cladding lateral plate (side fuel assembly & Temperature (IFA) \\
TF14 & fluid outlet (bottom of the core) & Temperature (IFA) \\
$\Delta \mathrm{P}$ & in dummy assembly & Temperature (IFA) \\
$\bar{u}$ & in dummy assembly & Pressure $(\Delta \mathrm{P}$ assembly) \\
& IFA location (see Figure 7$)$ & Coolant velocity $(\Delta \mathrm{P}$ assembly) \\
& DFA location (see Figure 7$)$ & Position $(6,8)$ \\
\end{tabular}

multipurpose reactor, a $56 \mathrm{MW}$ reactor with slightly pressurized light water as the primary coolant and moderator and heavy water as reflector $[28,34]$. The reactor core contains 21 plate type fuel assemblies of which 17 are standard assemblies and 4 are open assemblies for different purposes. The heat removal is conducted through downward coolant flow. Each standard fuel assembly has 20 fuel plates conforming 19 closed flow channels and other experimental channels [7,
28, 34]. Figure 7 displays a top view of the CARR reactor and detailed information about its geometry and operational conditions is found in Appendix A.

Thermal-hydraulic analyses for the CARR reactor under steady and transient conditions were carried out by Lei and Zhang [7]. They report a steady-state multichannel analysis furnishing calculated results for each fuel assembly of assembly flow rate and temperature distribution along 


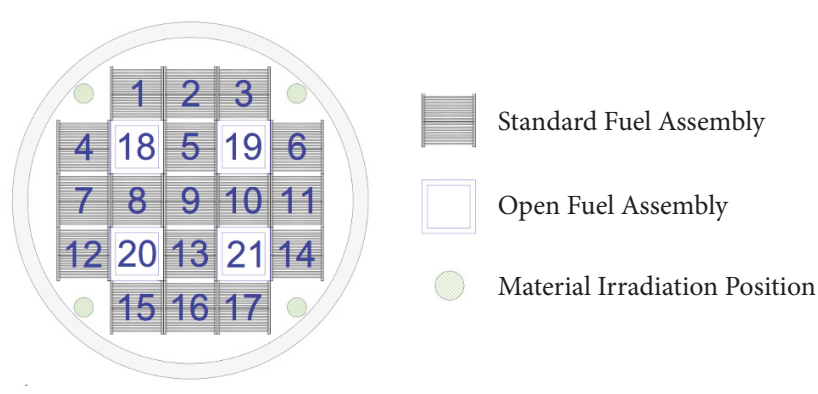

Figure 7: Top view of the CARR multipurpose reactor.

the hot coolant channel (axial direction). They also provide information about DNBR [7].

3.3. Validation Approach. The goal of this validation of the COTENP code is determining discrepancies of its calculated subchannel results compared to experimental data from the IEA-R1 research reactor and calculated results from the CARR multipurpose reactor. The discrepancy is defined here as the relative difference taking the reported results as the reference ones, i.e.,

$$
\text { discrepancy }=\frac{\mathrm{v}_{\text {COTENP }}-\mathrm{v}_{\text {Ref }}}{v_{\text {Ref }}}
$$

where $\mathrm{v}_{\text {COTENP }}$ is the COTENP code result and $\mathrm{v}_{\text {Ref }}$ is the IEA-R1 experimental results or [7] results. The mean discrepancy presented is the square root of the mean of the squared discrepancies or

$$
\text { mean discrepancy }=\sqrt{\frac{1}{I} \sum_{i=1}^{I}\left(\frac{\mathrm{v}_{\text {COTENP }, i}-\mathrm{v}_{\text {Ref }, i}}{\mathrm{v}_{\text {Ref }, i}}\right)^{2}}
$$

3.3.1. The IEA-R1 Model with the COTENP Code. The IEAR1 reactor analyses performed with the COTENP code considered the core configuration 243 in three different states: power levels at $5 \mathrm{MW}, 4.5 \mathrm{MW}$, and $4 \mathrm{MW}$. It considers results from Instrumented Fuel Assembly positioned at locations $(6,8)$ for temperature comparisons. The core pressure drop measurement is located at positions $(0,0)$ as shown in Figure 5.

The IFA is divided in three regions with 6 fuel plates each identified as fuel assembly side, central plate, and reflector side. The IFA model comprises 17 subchannels and 30 control volumes in the axial direction to represent the fuel assembly. The IFA power level $\mathrm{P}_{\text {IFA }}$ is obtained from

$$
P_{I F A}=\dot{m}_{I F A} c_{p}\left(T_{\text {out }}-T_{\text {in }}\right)
$$

where $\dot{m}_{I F A}$ is the coolant flow rate in the IFA, $c_{p}$ is the coolant specific heat, and $T_{\text {in }}$ and $T_{\text {out }}$ are the inlet (TF1) and outlet (TF14) coolant temperatures for the IFA. The reactor operational conditions for the three states considered including the power density distribution are presented in Appendix A [22].
The pressure drop for the IFA model takes into account the friction losses along the coolant channel and elevation acceleration since it is a downward flow. We consider no form losses along the channel, even considering that they may be significant, because of lack of information in the experimental data [22]. The acceleration losses and gains in the inlet and outlet are also neglected for similar reasons [22].

3.3.2. The CARR Model with the COTENP Code. The CARR reactor analysis includes the evaluation and comparison of the mass flow rate distribution among the fuel assemblies, coolant, cladding, and fuel centerline temperature distribution along the subchannels on the hot fuel assembly, and results for the departure from nucleate boiling ratio for the hot channel.

In addition, we present for this reactor some capabilities of the COTENP code such as identification of hot assembly based on enthalpy rise, pressure drop, thermodynamic quality, detailed temperature distribution, and results for the onset from nucleate boiling (ONB).

The CARR reactor simulation comprises the active zone with height of $850 \mathrm{~mm}$ where each fuel assembly is considered as a subchannel divided into 17 control volumes. In Appendix A we present the reactor operation data and the power density distribution as power factors for each fuel assembly and as axial distribution for both types of fuel assemblies [7].

The pressure drop model for the CARR reactor considered similar assumptions as those for the IFA in Section 3.3.1 since no information was reported [7].

\section{Results and Discussions}

4.1. Validation of the COTENP Code against Experimental Results from the IEA-R1 Research Reactor. Calculated thermal-hydraulic results obtained with the COTENP code for configuration 243 from the IEA-R1 reactor are compared in this section with experimental results $[22,26]$. The thermal-hydraulic variables at 3 different power levels are temperature (10 different IFA locations), coolant velocity, and pressure drop ( $\triangle \mathrm{P}$ dummy assembly location) as described in Sections 3.1 and 3.3 with locations presented in Figure 5 and Table 1.

In Table 2 we present results for the coolant and cladding temperature at different location of the IFA for $4 \mathrm{MW}$, 4.5 MW, and $5 \mathrm{MW}$. The calculated results at steady-state condition for the IEA-R1 reactor are compared against experimental data through relative difference between them [26]. The experimental error for the temperature measurements, as discussed in Section 3.1, is taken as $0.25^{\circ} \mathrm{C}$ or about $0.5 \%$. The comparisons yield mean discrepancies varying between $4.1 \%$ and $5 \%$. Relative discrepancies between calculation and measurement at each location are also presented and vary between 0.1 and $11 \%$. The maximum discrepancy for the 3 power levels occur at the same measurement location (TC3) at $252,5 \mathrm{~mm}$ from the top.

The results for the IFA power, coolant velocity, and pressure drop are shown in Table 3 for similar power levels. 
TABLE 2: Temperature results obtained with the COTENP code for the IEA-R1 reactor at different power levels. Temperature results simulate measurement results at different locations of the IFA. The IFA is located at the $(6,8)$ position. Inferred error from experimental results is \pm $0.25^{\circ} \mathrm{C}$ or $\pm 0.5 \%$.

\begin{tabular}{|c|c|c|c|c|c|c|c|c|c|}
\hline \multicolumn{10}{|c|}{ Temperature $\left({ }^{\circ} \mathrm{C}\right)$} \\
\hline & \multicolumn{3}{|c|}{ Power level = $4 \mathrm{MW}$} & \multicolumn{3}{|c|}{ Power level $=4.5 \mathrm{MW}$} & \multicolumn{3}{|c|}{ Power level $=5 \mathrm{MW}$} \\
\hline & Experimental & COTENP & $\begin{array}{c}\text { Discrepancy } \\
(\%)\end{array}$ & Experimental & COTENP & $\begin{array}{c}\text { Discrepancy } \\
(\%)\end{array}$ & Experimental & COTENP & $\begin{array}{c}\text { Discrepancy } \\
(\%)\end{array}$ \\
\hline TC2 & 44.41 & 43.60 & 1.8 & 46.47 & 45.50 & 2.1 & 48.72 & 47.60 & 2.3 \\
\hline TC3 & 37.28 & 41.20 & 10 & 38.68 & 42.90 & 11 & 40.30 & 44.80 & 11 \\
\hline TC4 & 45.27 & 42.70 & 5.7 & 47.29 & 44.35 & 6.2 & 49.57 & 46.50 & 6.2 \\
\hline TC5 & 49.25 & 49.35 & 0.2 & 51.78 & 51.80 & 0.1 & 54.56 & 54.30 & 0.5 \\
\hline TC6 & 42.95 & 45.85 & 6.7 & 44.87 & 48.00 & 7 & 47.01 & 50.25 & 6.9 \\
\hline TC7 & 50.51 & 48.05 & 4.9 & 53.02 & 50.25 & 5.2 & 55.85 & 52.75 & 5.5 \\
\hline TC8 & 45.99 & 46.45 & 1.0 & 48.22 & 48.75 & 1.1 & 50.69 & 50.95 & 0.5 \\
\hline TC10 & 42.02 & 43.55 & 3.6 & 42.81 & 45.45 & 6.2 & 44.90 & 47.60 & 6.1 \\
\hline TC12 & 47.64 & 45.30 & 4.9 & 43.92 & 47.40 & 8 & 46.08 & 49.65 & 7.7 \\
\hline TF14 & 37.28 & 36.71 & 1.5 & 38.70 & 38.10 & 1.6 & 40.34 & 39.15 & 2.9 \\
\hline $\begin{array}{l}\text { Root l } \\
(\%)\end{array}$ & an Square Di & repancy & 4.1 & & & 4.8 & & & 5.0 \\
\hline
\end{tabular}

TABLE 3: IFA power, coolant velocity, and IFA pressure drop at different power levels of the IEA-R1 reactor*. The IFA is located at the $(6,8)$ position.

\begin{tabular}{|c|c|c|c|c|c|c|c|c|c|}
\hline & \multicolumn{3}{|c|}{ Power level $=4 \mathrm{MW}$} & \multicolumn{3}{|c|}{ Power level $=4.5 \mathrm{MW}$} & \multicolumn{3}{|c|}{ Power level $=5 \mathrm{MW}$} \\
\hline & Experimental & COTENP & $\begin{array}{c}\text { Discrepancy } \\
(\%)\end{array}$ & Experimental & COTENP & $\begin{array}{c}\text { Discrepancy } \\
(\%)\end{array}$ & Experimental & COTENP & $\begin{array}{c}\text { Discrepancy } \\
(\%)\end{array}$ \\
\hline $\begin{array}{l}\text { IFA Power } \\
(\mathrm{kW})\end{array}$ & 147.61 & 143.40 & 2.9 & 162.39 & 158.26 & 2.6 & 177.53 & 154.29 & 13.2 \\
\hline $\begin{array}{l}\text { Coolant } \\
\text { velocity }(\mathrm{m} / \mathrm{s})\end{array}$ & 1.920 & 1.946 & 1.4 & 1.920 & 1.948 & 1.5 & 1.920 & 1.949 & 1.5 \\
\hline $\begin{array}{l}\text { Pressure drop } \\
(\mathrm{kPa})\end{array}$ & 7.835 & 7.00 & 10.7 & 7.835 & 7.0 & 10.7 & 7.835 & 7.0 & 10.7 \\
\hline
\end{tabular}

${ }^{*}$ The experimental errors were not reported.

The IFA power maximum discrepancy occurs for $5 \mathrm{MW}$ (13.2\%) while for the other 2 power levels it is below $2.9 \%$, the coolant velocity discrepancies are below $1.5 \%$, and pressure drop discrepancy are all equal to $10.7 \%$.

4.1.1. Discussion. The maximum discrepancy for the temperature was observed at the central channel of the assembly at position TC3. According to Hainoun et al. [22] similar evaluations of this problem conducted by other researchers using CATHARE, RELAP5, MERSAT, and PARET presented similar discrepancies at this location during the IAEA benchmark study conducted for the IEA-R1 reactor $[22,26]$. On the other hand, their average discrepancy for the several temperature measurements were $8.8 \%, 4.8 \%, 4.9 \%$, and $9.2 \%$, respectively, which are similar to those obtained with the COTENP code presented in Table 2 (root mean square discrepancy below 5\%) [22].

About the TC3 experimental temperature result, the researchers have concluded that the discrepancy at this location may possibly be due to the experimental data [22,
26]. Additionally one may consider that at this location the axial power factor is strongly affected by the control rods, which are inserted in the core up to this depth. A local variation in the power density distribution may influence the local temperature results $[35,36]$.

The coolant velocity and pressure drop for the 3 power level conditions presented similar discrepancies, below $1.5 \%$ and $10.7 \%$, respectively. The IFA power results at $4 \mathrm{MW}$ and $4.5 \mathrm{MW}$ presented discrepancies below $2.9 \%$ while at 5 MW the discrepancy increased to $13.2 \%$ although all other results discrepancies remained similar. The $5 \mathrm{MW}$ IFA power comparison requires further study.

The pressure drop discrepancy is important and should be discussed. The COTENP results take into account only friction losses and elevation acceleration for the downward flow. The difference may be due to neglecting the form loss and gain in the inlet and outlet of the coolant subchannel (see Section 3.3.1). Most probably the pressure drop measurement was made outside the coolant channel and would include these form effects. The $10 \%$ error indicates that the friction losses appear adequately considered. Further validation 


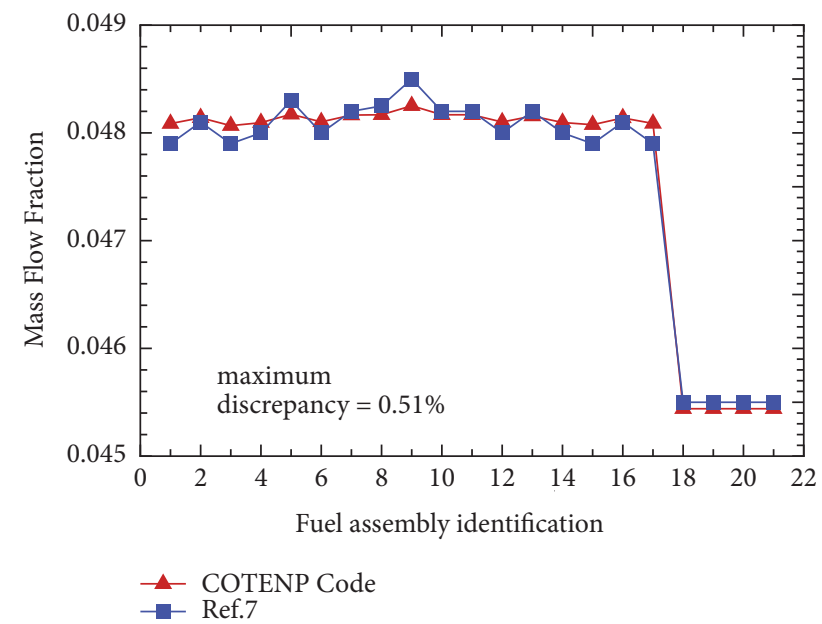

FIgURE 8: Mass flow rate fraction for the several fuel assemblies of the CARR reactor. Comparison between the COTENP code and [7].

appears necessary for better assessing the accuracy of the COTENP code.

4.2. Validation of COTENP Code against Calculated Results from the CARR Research Reactor. The thermal-hydraulic variables verified in this section are the mass flow rate in each fuel assembly, axial temperature distributions, and DNBR results obtained with the COTENP code for the CARR multipurpose reactor. The COTENP code results are compared with those reported by Lei and Zhang [7].

The results of thermodynamic quality and pressure drop along the hot FA are presented in Table 4; it shows that during steady-state operation of the reactor core there is no occurrence of two-phase flow at respective local pressure.

Figure 8 compares the mass flow rate at each fuel assembly obtained with the COTENP code and those reported by Lei and Zhang [7]. The flow rate distribution among the several fuel assemblies presents maximum discrepancy of about $0.51 \%$ and negligible mean average discrepancy. The pressure drop and coolant mean velocity calculated with the COTENP are $0.767 \mathrm{MPa}$ and $10.28 \mathrm{~m} / \mathrm{s}$, respectively. The discrepancies when compared to reported results are $9.7 \%$ for the pressure drop and $1.8 \%$ for the mean velocity.

Figure 9 compares results of axial temperature distribution in the hot channel at the fuel centerline, cladding, and coolant region from the COTENP code and Lei and Zhang [7]. The outlet coolant temperature calculated by the COTENP code is $70.2^{\circ} \mathrm{C}$ while the reported value is $68^{\circ} \mathrm{C}$ with $3.2 \%$ discrepancy. The mean and maximum relative discrepancies for the coolant, cladding, and fuel center line temperature distributions are presented in Figure 9.

Figure 10 compares the DNBR results near the region of heat transfer condition of minimum departure from nucleate boiling ratio. The results obtained from the COTENP code and those from [7] present similar trends with minimum DNBR equal to 9 and 11, respectively.

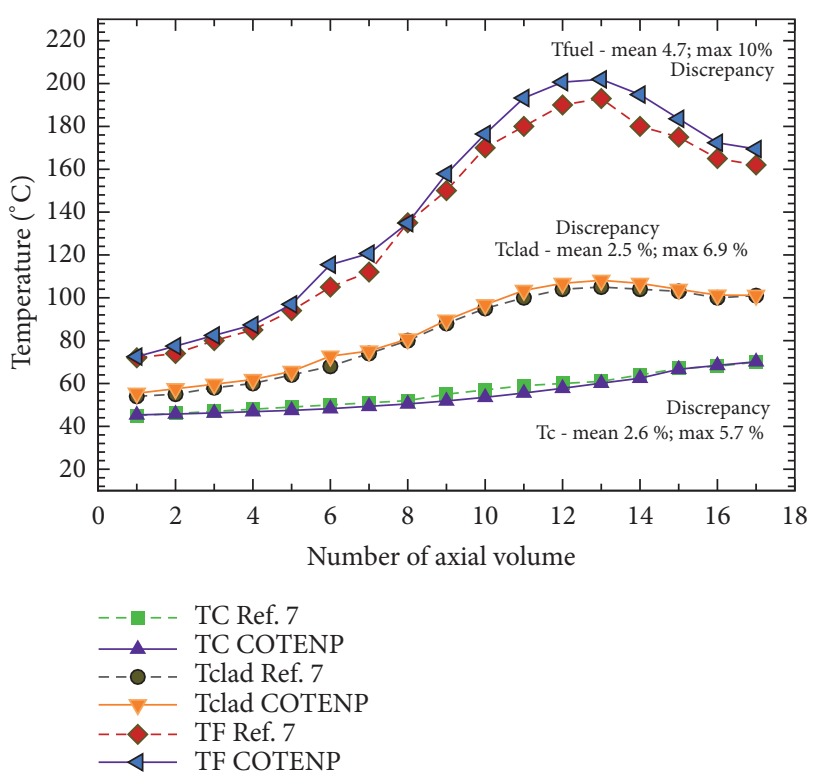

FIGURE 9: Comparison of the temperature distribution in the hot channel of the CARR reactor between the COTENP code and reported results [7]. TF is the centerline temperature, Tclad is the cladding temperature, and TC is the coolant temperature.

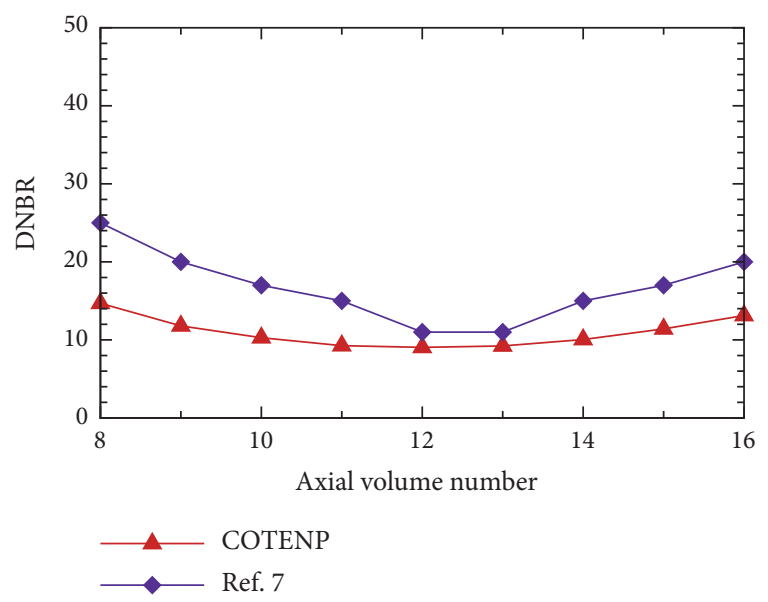

FIGURE 10: Comparison of DNBR results in the hottest fuel assembly for the CARR reactor between the COTENP code and reported results [7].

4.2.1. Discussion. Regarding the mass flow rate variable for different fuel assemblies, the COTENP code results compare well with those from [7] since the mean discrepancy is negligible and the maximum discrepancy is small (0.51\%). Taking into account the fact that the mass flow rate distribution depends on the pressure drop, the adjusting procedure through the coolant velocity in each fuel assembly subchannel (see Section 2.3) appears as good model. The large pressure drop discrepancy (9.7\%), similar to that observed in the IEA-R1 reactor analysis presented in Section 4.1, seems to emphasize that the justification for the difference lies in not accounting for form losses in the inlet and outlet of the coolant channel. As was mentioned in Section 3.3.2, the 
TABLE 4: Thermodynamic quality and pressure drop in the hot fuel assembly from the CARR reactor.

\begin{tabular}{lccc}
\hline Control volume & Core height $(\mathrm{mm})$ & Thermodynamic quality & Pressure $(\mathrm{kPa})$ \\
\hline 1 & 50 & $-1.14 \mathrm{E}-03$ & 628.255 \\
2 & 100 & $-1.13 \mathrm{E}-03$ & 636.55 \\
3 & 150 & $-1.10 \mathrm{E}-03$ & 644.89 \\
4 & 200 & $-1.06 \mathrm{E}-03$ & 653.282 \\
5 & 250 & $-9.90 \mathrm{E}-04$ & 661.732 \\
6 & 300 & $-9.01 \mathrm{E}-04$ & 670.245 \\
7 & 350 & $-7.94 \mathrm{E}-04$ & 678.823 \\
8 & 400 & $-6.78 \mathrm{E}-04$ & 687.463 \\
9 & 450 & $-5.63 \mathrm{E}-04$ & 696.161 \\
10 & 500 & $-4.60 \mathrm{E}-04$ & 704.908 \\
11 & 550 & $-3.70 \mathrm{E}-04$ & 713.696 \\
12 & 600 & $-2.86 \mathrm{E}-04$ & 722.521 \\
13 & 650 & $-2.13 \mathrm{E}-04$ & 731.378 \\
14 & 700 & $-1.54 \mathrm{E}-04$ & 740.261 \\
15 & 750 & $-1.04 \mathrm{E}-04$ & 749.165 \\
16 & 800 & $-5.86 \mathrm{E}-05$ & 758.088 \\
17 & 850 & $-1.86 \mathrm{E}-05$ & 767.029 \\
\hline
\end{tabular}

CARR model did not account for such effects due to lack of information.

The axial temperature distributions for the coolant, cladding, and fuel centerline present similar shapes to those from Lei and Zhang [7]. The mean discrepancy below $2.6 \%$ for the coolant and cladding temperatures is not reproduced for the fuel centerline. This is due to the approximation of uniform temperature conductivity in the fuel region. The consequence is that the peak fuel temperature produced by the COTENP code is $202^{\circ} \mathrm{C}$ while Lei and Zhang [7] report $193^{\circ} \mathrm{C}$.

The differences presented by the DNB ratio from the COTENP code and those from [7] in Figure 11 can be considered small and can be attributed to the different critical heat flux correlations utilized by the two codes and the small differences on the local temperature and pressure results produced by the two calculations (see the coolant and cladding temperature results for axial volumes 12 and 13 in Figure 9).

The outlet flow quality for the hot channel is all negative as shown in Table 4 indicating that no saturated boiling had occurred. In this regard the two-phase flow model implemented in the COTENP code could not be validated with the CARR results.

4.3. Other Results Furnished by the COTENP Code. Beside the thermal-hydraulic variable shown in the previous sections, the COTENP code furnishes additional information about onset from nucleate boiling condition (ONB), which is important for typical research reactors, departure from nucleate boiling, and enthalpy rise. Such results are presented below for the CARR multipurpose reactor.

The onset of nucleate boiling can be found observing the trend of the wall superheat temperature versus heat flux

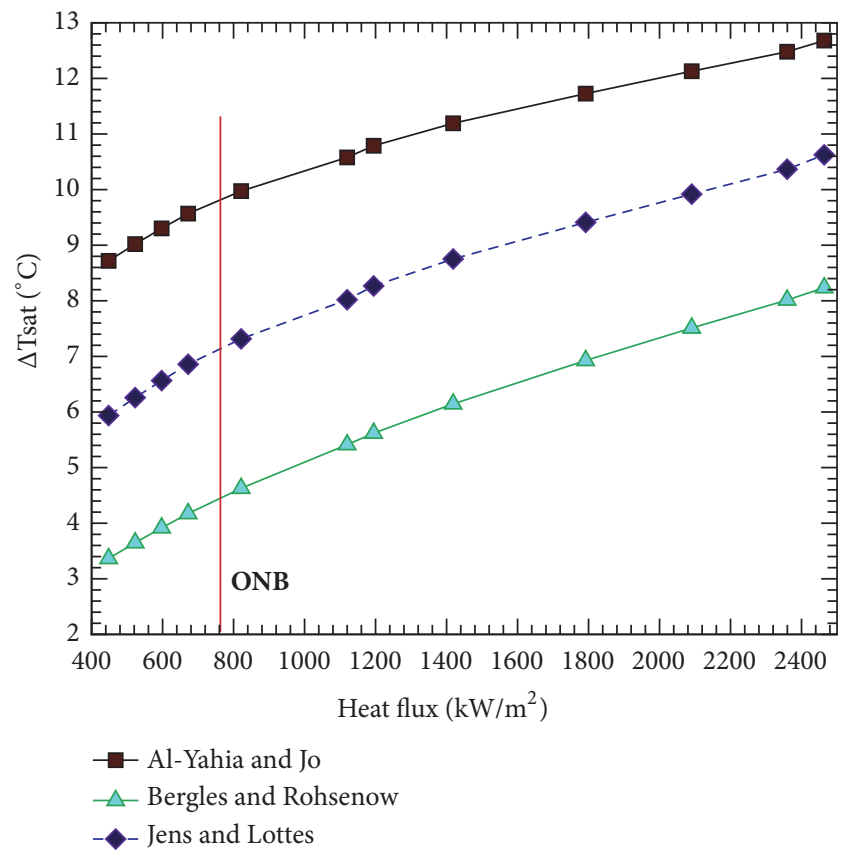

FIGURE 11: Variation in the wall superheat temperature with heat flux for the proposed correlations.

as shown in Figure 11. The slope of the wall temperature reduces around the ONB location as shown by the trend lines for low and high heat fluxes for the 3 correlations considered, Al-Yahia and Jo, Bergles and Rohsenaw, and Jens and Lottes. These correlations indicate that the onset of nucleate boiling occurs for heat fluxes just below $800 \mathrm{~kW} / \mathrm{m}^{2}$. The wall superheat temperature varies between $3^{\circ} \mathrm{C}$ and $9^{\circ} \mathrm{C}$. This point occurs at control volume number 5 at $250 \mathrm{~mm}$ from the subchannel inlet. 


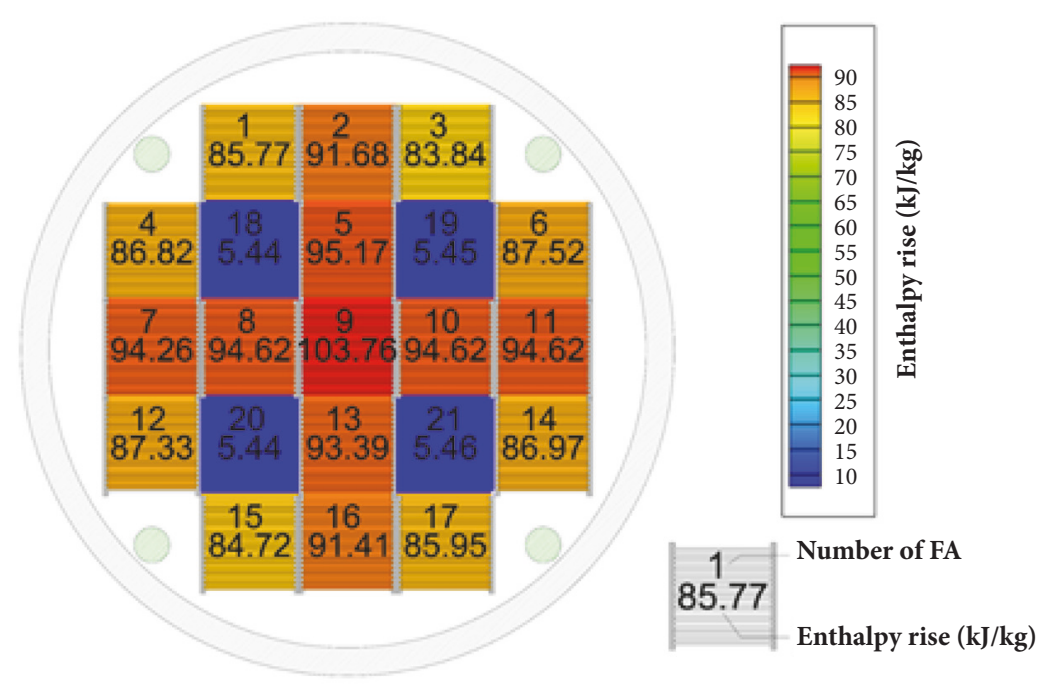

FIGURE 12: Enthalpy rise for the several fuel assemblies of the CARR reactor obtained with the COTENP code.

The homogeneous equilibrium two-phase flow model utilized in the COTENP code accounts for saturated boiling but not for local subcooled nucleate boiling in the coolant. Thus these local effects on the pressure drop, local coolant specific mass, local wall temperature, and local heat flux are not accounted for in the results presented in Figures 10 and 11 in the current COTENP code model.

Figure 12 displays the enthalpy rise for the several fuel assemblies of the CARR multipurpose reactor. The FA with largest enthalpy rise is the number 9 with $103.76 \mathrm{~kJ} / \mathrm{kg}$.

\section{Conclusions}

The COTENP code was developed for thermal-hydraulic design evaluation of nuclear reactors with plate type fuel assemblies. It is a subchannel analysis code based on conservation equations for mass, momentum, and energy which calculates the flow and temperature distributions in plate type fuel assemblies for steady-state conditions. It furnishes detail information about mass flow rate distribution, core pressure drop, average coolant velocity, and temperature distributions. Regarding design parameters it identifies the hot channel, fuel, cladding and coolant maximum temperatures, and information about onset of nucleate boiling (ONB) and departure from boiling ratio (DNBR). The COTENP code accuracy was verified through comparisons with measured results from the IEA-R1 research reactor and comparisons with calculated results from the CARR multipurpose reactor.

The mean discrepancies for the coolant temperature at different power level conditions were below 5\% for the Benchmark Database from the IEA-R1 research reactor of the International Atomic Energy Agency. The COTENP code presented good results. The pressure drop and coolant velocity presented discrepancies below $1.5 \%$ and $10.7 \%$, respectively. These results indicate that the model for pressure drop and coolant velocity takes into account correctly the friction losses along the channel and that the 10.7\% discrepancy should be due the disregard of form losses in the channel inlet and outlet due to lack of detailed information in the experimental data.

The validation of the COTENP code against calculated results from the CARR multipurpose reactor has evidenced good results for the flow rate distribution among the fuel assemblies and for the coolant temperature axial distribution. The former presented negligible mean discrepancy and the latter presented mean discrepancy of $2.6 \%$ which is about half of that presented in the validation against the IEA-R1 reactor experimental data. The pressure drop result presented a discrepancy of $9.7 \%$, similar to that presented in the IEAR1 reactor validation. This result emphasizes the need to verify results including form effects on the pressure drop in the coolant channel inlet and outlet. The COTENP code presented good estimation of the DNB ratio for the CARR multipurpose reactor.

These two verifications of the COTENP code presented good results indicating that with additional improvements it can be used for verifying thermal-hydraulic limits of the planned Brazilian multipurpose reactor. Appendix A lists the improvements planned to be implemented in the code.

\section{Appendix}

\section{A.}

A.1. Data from the IEA-R1 Reactor. Table 5 summarizes the main parameters describing the IEA-R1 reactor. The reactor 
TABLE 5: Main description parameters of IEA-R1 research reactor [22, 26].

\begin{tabular}{|c|c|c|}
\hline Reactor parameter & Data & Note \\
\hline Thermal power reactor $[\mathrm{MW}]$ & $2-5$ & Depends on irradiation program \\
\hline Number of Fuel assembly & 24 & \\
\hline (i) Standard FA & 20 & \\
\hline (ii) Control FA & 4 & \\
\hline Total coolant flow rate $\left[\mathrm{m}^{3} / \mathrm{h}\right]$ & 772 & \\
\hline Bypass flow rate $\left[\mathrm{m}^{3} / \mathrm{h}\right]$ & 547.2 & \\
\hline Coolant flow rate of FA $\left[\mathrm{m}^{3} / \mathrm{h}\right]$ & 22.8 & \\
\hline Inlet Pressure [Mpa] & 0.17 & \\
\hline Inlet temperature $\left[{ }^{\circ} \mathrm{C}\right]$ & $31.67 / 32.50 / 32.53$ & For $4.0 / 4.5 / 5.0[\mathrm{MW}]$ respectively \\
\hline Power Density $\left[\mathrm{W} / \mathrm{cm}^{3}\right]$ & $143 / 158 / 172$ & For $4.0 / 4.5 / 5.0[\mathrm{MW}]$ respectively \\
\hline \multicolumn{3}{|l|}{ Number of fuel plates: } \\
\hline (i) Standard FA & 18 & \\
\hline (ii) Control FA & 12 & \\
\hline Fuel meat dimensions $\left(\mathrm{U}_{3} \mathrm{Si}_{2}-\mathrm{Al}\right.$ or $\left.\mathrm{U}_{3} \mathrm{O}_{8}-\mathrm{Al}\right)[\mathrm{mm}]$ & $0.76 \times 62.6 \times 600$ & \\
\hline Thickness of coolant channel [mm] & 2.89 & \\
\hline Clad thickness $[\mathrm{mm}]$ & 0.38 & \\
\hline
\end{tabular}

${ }^{*}$ FA, Fuel assembly.

TABLE 6: Main operational and geometric parameters of CARR research reactor [7, 28].

\begin{tabular}{|c|c|c|}
\hline Reactor parameter & Data & Note \\
\hline Thermal power reactor $\left[\mathrm{MW}_{\mathrm{th}}\right]$ & 56 & Depends on irradiation necessity \\
\hline Number of Fuel assembly & 21 & \\
\hline (i) Standard FA & 17 & \\
\hline (ii) Open FA & 4 & \\
\hline Total coolant flow rate $\left[\mathrm{m}^{3} / \mathrm{h}\right]$ & 2650 & \\
\hline Outlet Pressure [Mpa] & 0.62 & \\
\hline Inlet temperature $\left[{ }^{\circ} \mathrm{C}\right]$ & 45 & \\
\hline Power Density $\left[\mathrm{W} / \mathrm{cm}^{3}\right]$ & 568 & \\
\hline Core radius $[\mathrm{m}]$ & 0.4 & \\
\hline Height of active area $[\mathrm{m}]$ & 0.85 & \\
\hline \multicolumn{3}{|l|}{ Number of fuel plates: } \\
\hline (i) Standard FA & 21 & \\
\hline Fuel meat dimensions [mm] & $0.76 \times 77.2 \times 850$ & Data taken from $[28,29]$ \\
\hline Thickness of coolant channel [mm] & 2.59 & {$[29]$} \\
\hline Clad thickness $[\mathrm{mm}]$ & 0.38 & [29] \\
\hline Thermal conductivity of $\mathrm{U}_{3} \mathrm{Si}_{2}-\mathrm{Al}[\mathrm{W} / \mathrm{m} \mathrm{K}]$ & 50.03 & {$[28]$} \\
\hline Clad thermal conductivity [W/m K] & 176.01 & {$[28]$} \\
\hline
\end{tabular}

${ }^{*}$ FA, Fuel assembly.

holds to types of plate type of dispersion fuels: $\mathrm{U}_{3} \mathrm{Si}_{2}-\mathrm{Al}$ and $\mathrm{U}_{3} \mathrm{O}_{8}$-Al. The fuel is the Instrumented Fuel Assembly (IFA) which was designed and manufactured to perform measurements of different core cooling parameters in actual reactor conditions. It was used to validate computer codes used in the safety analysis of the IEA-R1 reactor [26]. The IFA has three regions comprising 6 plates each. The transverse power factors assumed for the regions are 1.0 for the fuel assembly side, 0.89 for the central plates, and 0.96 for the reflector side. Figure 13 shows the normalized axial power distribution for the 3 regions of the IFA and Figure 14 shows the average power factors for the fuel assemblies.
A.2. Data from the CARR Research Reactor. The CARR reactor has a $\mathrm{U}_{3} \mathrm{Si}_{2}-\mathrm{Al}$ dispersion type fuel. Table 6 presents the main parameters describing the CARR research reactor. Figure 15 shows the radial power fuel assembly and the axial power distribution for both types of fuel assemblies.

A.3. Future Improvements. The future improvements planned to be implemented in the COTENP code include an improved model for two-phase flow, for estimating the pressure drop, allow nonuniform temperature across the fuel meat, estimating the coolant critical velocity in the hot subchannel, additional means to calculate critical heat flux, 


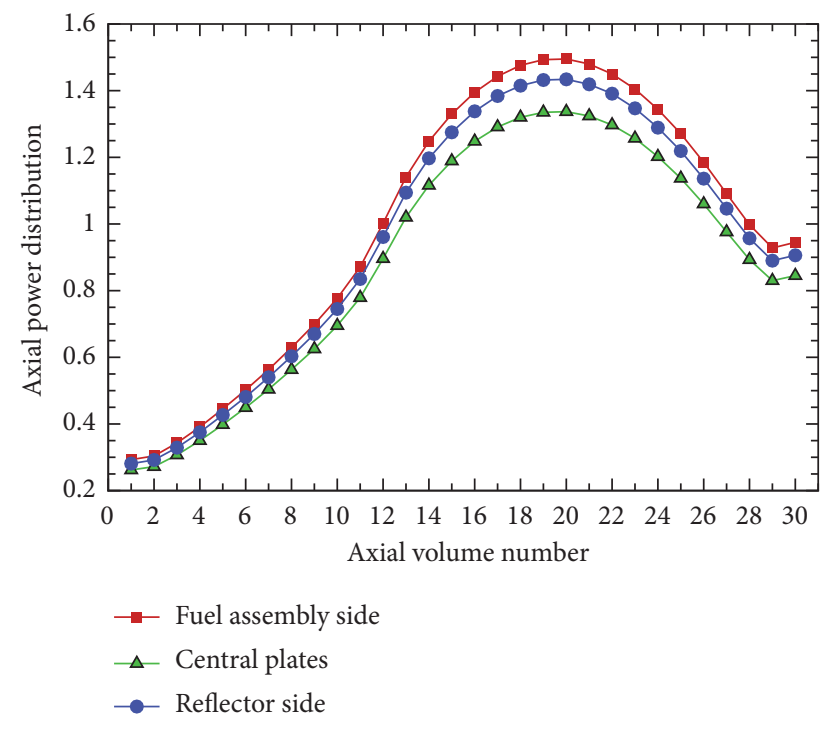

FIgURE 13: Axial power distribution in the Instrumented Fuel Assembly [26].

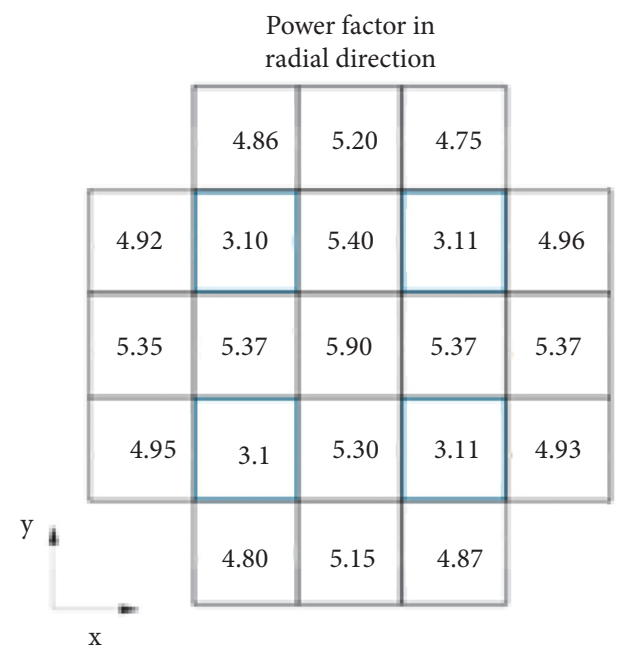

FIGURE 14: Average fuel assembly power factors from the CARR reactor [7].

for instance, look-up tables, qualifying the input, and discuss uncertain factors.

\section{Nomenclature}

A: $\quad$ Cross section area of the subchannel $\left(\mathrm{m}^{2}\right)$

AVD: Average relative derivation

c: Cladding thickness

$\mathrm{C}^{*}$ : $\quad$ Heat capacity of the coolant

CHF: Critical Heat Flux

$D_{h}: \quad$ Hydraulic diameter

DNBR: Departure from nucleate boiling ratio

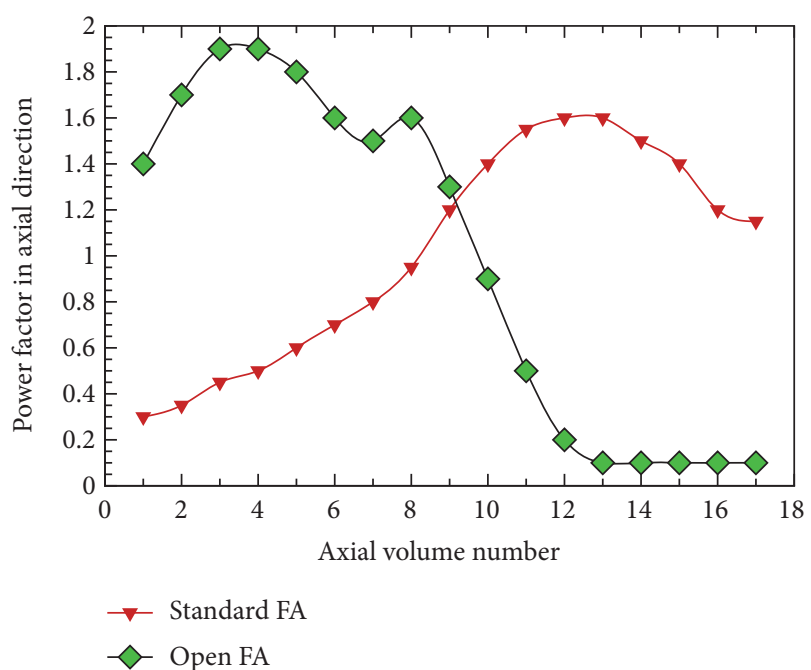

FIgURe 15: Axial power factors for the standard and open fuel assemblies from the CARR reactor [7].

$f: \quad$ Friction coefficient

FA: Fuel assemblies

$F_{z, i}^{N}: \quad$ Axial power distribution factor in the volume control

$F_{R, i}^{N}: \quad$ Radial power distribution factor in the subchannel

$\bar{h}: \quad$ Coolant enthalpy $(\mathrm{J} / \mathrm{kg})$

$h_{c}$ : Heat transfer coefficient of coolant

IFA: Instrumented Fuel Assembly

$k_{k, i}: \quad$ Localized form loss coefficient

$k_{\text {cool }}$ : Thermal conductivity of the fluid

$k_{f u e l}$ : Thermal conductivity of the fuel

$\dot{m}: \quad$ Mass flow rate $(\mathrm{kg} / \mathrm{s})$

PWR: Pressurized Water Reactors

$P_{a}: \quad$ Heated perimeter of the subchannel (m)

$\Delta P:$ Pressure drop

$q_{x}^{\prime \prime}: \quad$ Heat flux across the surface area of the fuel plate $\left(\mathrm{W} / \mathrm{m}^{2}\right)$

$q^{\prime \prime \prime}:$ Power density $\left(\mathrm{W} / \mathrm{cm}^{3}\right)$

S: $\quad$ Half thickness of fuel

Tc: Coolant temperature

$\mathrm{T}_{\text {clad }}$ : Cladding temperature

$\mathrm{T}_{\mathrm{f}}$ : Fuel temperature

$\bar{u}: \quad$ Coolant speed $(\mathrm{m} / \mathrm{s})$

$\Delta \bar{u}_{j}: \quad$ Coolant speed change

$Z: \quad$ Node elevation in the subchannel

$\alpha_{i}: \quad$ Area relation $A_{i} / A_{T}$

$\rho: \quad$ Specific mass of the coolant $\left(\mathrm{kg} / \mathrm{m}^{3}\right)$

$\epsilon$ : Convergence criterion.

\section{Data Availability}

All data underlying this research are available upon request to the corresponding author. 


\section{Conflicts of Interest}

The authors declare that there are no conflicts of interest regarding the publication of this paper.

\section{Acknowledgments}

The authors want to acknowledge the financial support provided by Coordenação de Aperfeiçoamento de Pessoal de Nível Superior (CAPES) (a scholarship for Duvan A. Castellanos-Gonzalez), Conselho Nacional de Desenvolvimento Científico e Tecnológico $(\mathrm{CNPq})$, and Universidade Federal do ABC (UFABC).

\section{References}

[1] D. Thomas, Effects of variation of uranium enrichment on nuclear submarine reactor design [MSc. Thesis], Massachusetts Institute of Tecnology, Cambridge, MA, USA, 1990.

[2] L. S Tong and J. Weisman, "Safety analysis," in Thermal Analysis of Pressurized Water Reactor, American Nuclear Society, La Grange Park, IL, USA, 1996.

[3] M.-G. Kim, Y. Lee, and J. I. Lee, "Comparison of thermal hydraulic performances of rod-type fuel to plate-type fuel for small modular reactor application," in Proceedings of the International Congress on Advances in Nuclear Power Plants, ICAPP 2014, pp. 1885-1893, April 2014.

[4] M. K. Rowinski, T. J. White, and J. Zhao, "Small and medium sized reactors (SMR): a review of technology," Renewable \& Sustainable Energy Reviews, vol. 44, pp. 643-656, 2015.

[5] J. A. Perrotta, Proposta de um núcleo de reator PWR avançado com características adequadas para o conceito de segurança passiva, Tese de Doutorado, Instituto de Pesquisas Energéticas e Nucleares, São Paulo, Brazil, 1999.

[6] A. M. Saliba-Silva, E. F. Urano de Carvalho, H. G. Riella, and M. Durazzo, "Research reactor fuel fabrication to produce radioisotopes," in Radioisotopes - Applications in Physical Science, N. Singh, Ed., chapter 2, Intech Publisher, Rijeka, Croatia, 2011.

[7] L. Lei and Z. Zhang, "Development of Thermal;Hydraulic Analysis Code for Plate Type Fuel Reactor," Journal Institute of Electrical and Electronics Engineers, vol. 978, no. 1, pp. 48134818, 2010.

[8] G. Cuervo, Análisis termohidráulico de núcleos PWR con modelizacion de flujo bifásico para acoplamiento con la neutrónica. [Ph.D. thesis], Universidad Politécnica de Madrid, Madrid, Spain, 2007.

[9] N. E. Todreas and M. S. Kazimi, Nuclear Systems I, Thermal Hydraulic Fundamentals, chapter 2, Taylor \& Francis, Philadelphia, PA, USA, 1990.

[10] O. S. Al-Yahia and D. Jo, "Onset of Nucleate Boiling for subcooled flow through a one-side heated narrow rectangular channel," Annals of Nuclear Energy, vol. 109, pp. 30-40, 2017.

[11] H. Mochizuki and K. Muranaka, "Benchmark analyses for EBRII shutdown heat removal tests SHRT-17 and SHRT-45R - (2) subchannel analysis of instrumented fuel subassembly," Nuclear Engineering and Design, vol. 330, pp. 14-27, 2018.

[12] A. Toptan, N. W. Porter, R. K. Salko, and M. N. Avramova, "Implementation and assessment of wall friction models for LWR core analysis," Annals of Nuclear Energy, vol. 115, pp. 565$572,2018$.
[13] U. Imke and V. H. Sanchez, "Validation of the subchannel code SUBCHANFLOW using the NUPEC PWR tests (PSBT)," Science and Technology of Nuclear Installations, vol. 2012, 2012.

[14] N. Hammouda and Y. Rao, "The effect of the advanced driftflux model of ASSERT-PV on critical heat flux, flow and void distributions in CANDU bundle subchannels," Annals of Nuclear Energy, vol. 104, pp. 197-213, 2017.

[15] F. Lodi, G. Grasso, D. Mattioli, and M. Sumini, "ANTEO+: A subchannel code for thermal-hydraulic analysis of liquid metal cooled systems," Nuclear Engineering and Design, vol. 301, pp. $128-152,2016$.

[16] J. Johns and W. D. Reece, "Subchannel analysis of fuel temperature and departure of nucleate boiling of TRIGA Mark i," Annals of Nuclear Energy, vol. 75, pp. 331-339, 2015.

[17] J. Chao and J. Matos, "COBRA-3C/RERTR, Thermohydraulic low pressure subchannel transients analysis," Tech. Rep. NESC9978, Nuclear Energy Agency, 1992.

[18] K. Masanori, "COOLOD-N A computer code, for the analyses of Steady-state Thermal-hydraulic in Plate-Type Research Reactors," Japan Atomic Energy Research Institute, vol. 21, no. 18, 1990.

[19] Q. Lu, S. Qiu, and G. H. Su, "Development of a thermalhydraulic analysis code for research reactors with plate fuels," Annals of Nuclear Energy, vol. 36, no. 4, pp. 433-447, 2009.

[20] T. Hamidouche and A. Bousbia-Salah, "RELAP5/3.2 assessment against low pressure onset of flow instability in parallel heated channels," Annals of Nuclear Energy, vol. 33, no. 6, pp. 510-520, 2006.

[21] A. Hainoun, N. Ghazi, and B. M. Abdul-Moaiz, "Safety analysis of the IAEA reference research reactor during loss of flow accident using the code MERSAT," Nuclear Engineering and Design, vol. 240, no. 5, pp. 1132-1138, 2010.

[22] A. Hainoun, A. Doval, P. Umbehaun et al., "International benchmark study of advanced thermal hydraulic safety analysis codes against measurements on IEA-R1 research reactor," Nuclear Engineering and Design, vol. 280, pp. 233-250, 2014.

[23] D. Gong, S. Huang, G. Wang, and K. Wang, "Heat transfer calculation on plate-type fuel assembly of high flux research reactor," Science and Technology of Nuclear Installations, vol. 2015, Article ID 198654, 13 pages, 2015.

[24] J. M. L. Moreira and C. Andrezejewski, "Critérios de segurança para combustível tipo placa em reatores de pequeno porte," in Proceedings of the INAC-2005 International Nuclear Energy Conference, Associação Brasileira de Energia Nuclear, São Paulo, Brazil, 2005.

[25] H. V. Soares, I. D. Aronne, A. L. Costa, C. Pereira, and M. A. F. Veloso, "Analysis of Loss of Flow Events on Brazilian Multipurpose Reactor Using the Relap5 Code," International Journal of Nuclear Energy, vol. 2014, Article ID 186189, 12 pages, 2014.

[26] P. E. Umbehaun, D. A. Andrade, W. M. Torres, and W. RicciFilho, "Research Reactor Benchmarking Database: Facility Specification and experimental data IEA-R1 nuclear reactor (Brazil)," Tech. Rep. 408, 2014.

[27] N. E. Todreas and M. S. Kazimi, Nuclear Systems II, Elements of Thermal Hydraulic Design, Chapter 6, Taylor \& Francis, Philadelphia, PA, USA, 2001.

[28] F. Shen and L. Yuan, "Conceptual study of cold-neutron source in China Advanced Research Reactor," Physica B: Condensed Matter, vol. 311, no. 1-2, pp. 152-157, 2002.

[29] J. J. Duderstadt and L. J. Hamilton, “Thermal-hydraulic analysis of nuclear reactor cores," in Nuclear Reactor Analysis, John Wiley \& Sons, Hoboken, NJ, USA, 1st edition, 1976. 
[30] F. P. Incropera and D. P. Dewitt, Fundamentos de Transferencia de Calor, Pearson Pretince Hall, Mexico City, Mexico, 4th edition.

[31] M. M. El-Wakil, "Heat conduction in reactor elements," in Nuclear Heat Transport, International Textbook Company, Scranton, PA, USA, 1st edition, 1971.

[32] N. E. Todreas and M. S. Kazimi, Nuclear Systems I, Thermal Hydraulic Fundamentals, chapter 4, Taylor \& Francis, Philadelphia, PA, USA, 1990.

[33] S. C. Chapra and R. Canale, Métodos numéricos para ingenieros, chapter 18, McGraw-Hill, Mexico city, Mexico, 2006.

[34] W. Tian, S. Qiu, and Y. Guo, "Development of steady thermalhydraulic code for the China Advance Research Reactor," Energy Power Engineering, vol. 2, pp. 189-194, 2007.

[35] J. Moreira, "Space-time analysis of reactor-control-rod-worth measurements," Nuclear Science and Engineering, vol. 86, no. 1, pp. 91-105, 1984.

[36] J. Moreira and J. C. Lee, "Accuracy of the modal-local method for reactivity determination," Nuclear Science and Engineering, vol. 98 , no. 3, pp. 244-254, 1988. 

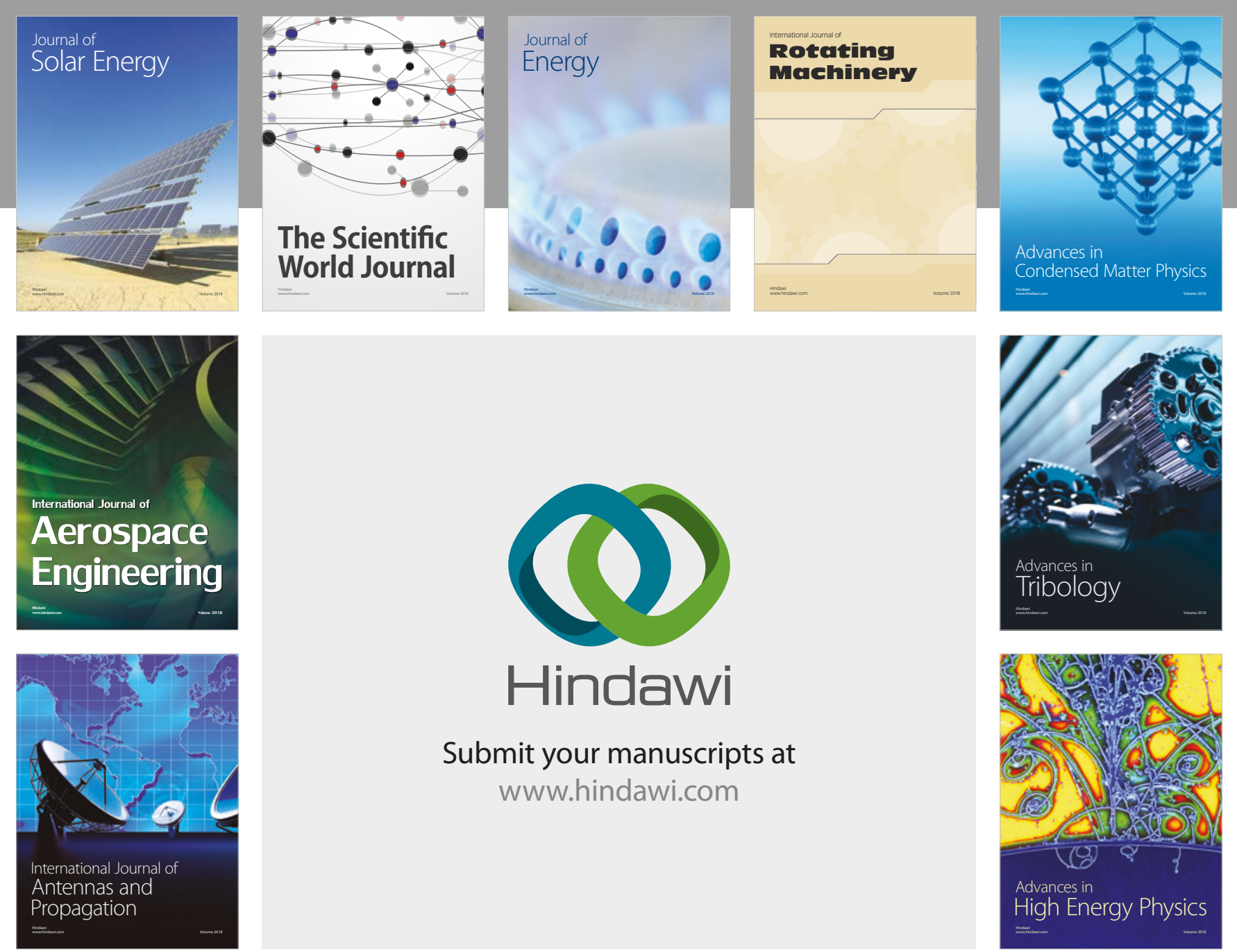

Submit your manuscripts at

www.hindawi.com
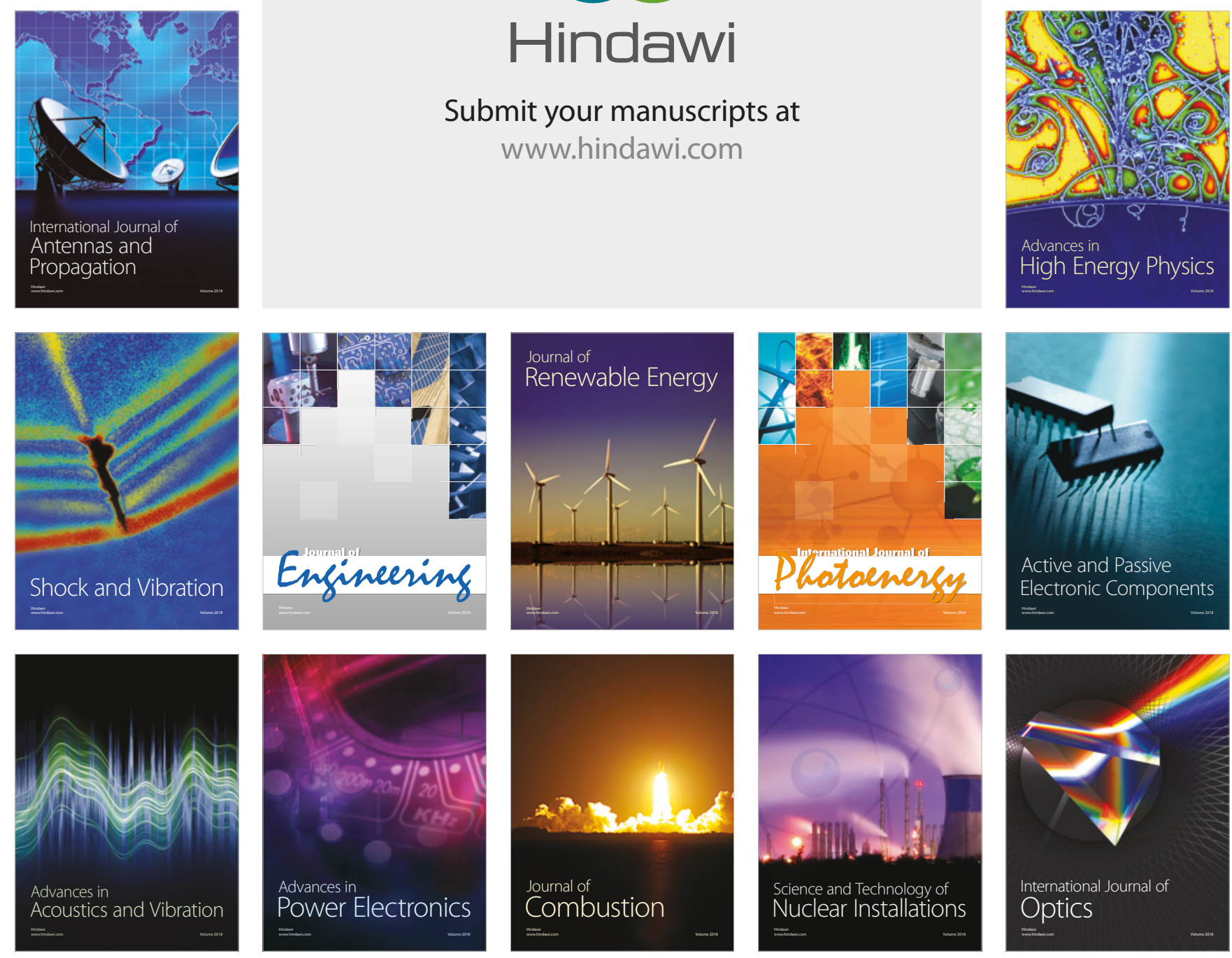